\title{
A Mini Review- Investigation and Study of Risks in Oil Pipeline Construction Substations
}

\author{
Priyanka EB*, Maheswari C and Thangavel S \\ Department of Mechatronics Engineering, Kongu Engineering College, India
}

*Corresponding author: Priyanka EB, Department of Mechatronics Engineering, Kongu Engineering College, Erode, 638060, India

\begin{abstract}
The era of oil and gas pipelines is enduring an informational renovation to recover enactment, minimalize ruptures and spills, and rise safety, and is fetching to resemble as an example of data-enabled substructure. Pipelines comes to the vision of public cognizance only when leak occurs, prominent to a toxic spill, or result in an explosion that outlays lives. The industry 4.0 is integrating sensing knowledge to monitor pressure, flow rate, pumping station parameters, temperature, viscosity, and other external parameters. The oil industry is habitually alienated into three foremost components: Upstream, midstream and Downstream. The midstream sector encompasses the transportation (by pipeline, rails, tanker or truck), loading, and comprehensive marketing of refined petroleum products. Pipelines can be incorporated to transport crude oil from primary production sites to corresponding refineries and distribute the several refined products to respective downstream distributors. Pipeline networks are tranquilized of several complex of equipment that function together to transfer refined oil products from main site to consumer location. This paper gives a short outline on the construction essentials and failure-risks rates involved in the construction of the oil pipeline substations.
\end{abstract}

Keywords: Oil pipelines; Substation construction and failure rates

\section{Introduction}

Pipelines are one of the most secure, most proficient and feasible approach to move natural assets of high volumes through land over long run of distance. Oil pipelines are commonly separated into two fundamental segments called trunks and gathering lines. Trunks go in size from 20 to 60 centimeters in width while gathering lines extend from 5 to 15 centimeters in measurement. Indeed, even at these huge diameters across, it takes a significant measure of power to push oil into the pipelines $[1,2]$.

Crude oil transportation is also partitioned into 'Gathering Lines' and 'Transmission Lines". A gathering pipeline conveyances crude oil refined product from a production maneuver to a transmission line. Gathering pipelines also do not convey the endowment of prominent domain and its size varies between 4 to 29 inches in diameter extent [3,4]. Administrators must acquire an assortment of important allows and hold fast to strict ecological assurance benchmarks to prepare for disintegration, consequent sedimentation, expanded rates or volumes of tempest water overflow, guarantee wetlands and conduits are secured, and dodge effects to uncommon, undermined and imperiled species and their natural surroundings. A transmission pipeline transports refined oil based commodities from a gathering pipelines, frequently over very long distances at more prominent volume and weight, to another storage space or a dissemination framework for distribution [5].

\section{Strategic and economic interest of oil pipeline system in India}

With a continuous emergent population growth leading to an enhanced level of life, energy ingesting is anticipated to proliferate every year: energy requirement predictions prepared by a number of protuberant organizations, comprising the International Energy Agency (IEA) and the World Energy Council, all come to an agreement in that fashion [6]. Bestowing to the IEA's base constraints, world mandate for prime energy should upsurge $21 \%$ by 2010 and $71 \%$ by 2030 , for a manipulated regular growth rate of $1.9 \%$ a year. To concealment this proliferation in world energy request, it will be mandatory to activate all energy resources especially hydrocarbons which plays a very noticeable part in challenging world energy necessities (66 versus 63\% today) [7]. To encounter these necessities, heavy crudes specified with magnitude of their current resources, will performance a more and more noteworthy role. Conferring to IEA, the current resources will requires $15 \%$ in the development of oil supply propagation between 2001 and 2030 . 
India witnessed stupendous development in oil refining part in the ongoing past [8]. India relies upon a system of more than 207,800 miles of fluids pipelines, more than 300,000 miles of gas transmission pipelines, and more than 2.1 million miles of oil distribution pipelines with more securely and productively move refined products in order to fuel our country's financial engine [9]. This nature of pipeline systems fills in as a national system to move the oil-based vitality assets on the requirements from production regions or ports of passage all through India to customers, airplane terminals, military bases, and industry consistently.

Cross-country pipelines are universally acknowledged as the innocuous, cost-efficient, energy-prominent and environmentfriendly mode for conveyance of crude oil and petroleum products [10]. As a innovator in oil pipelines in the nation, Indian Oil overseeing one of the world's biggest oil pipeline systems, accomplished the most astounding ever throughput of 85.68 million metric tons for each annum (MMTPA) amid the year 201718. With the acceptance of innovation in all fronts, this pipeline will wind up one of the technologically upgraded pipelines in the nation with the help of Supervisory Control and Data Acquisition (SCADA) framework to continually monitor the mobilization of petroleum products through the pipeline $[5,10]$. The trunk communication framework utilizes Optical Fiber Cable innovation for voice and data correspondence [11]. The network of 12 pumping stations and 19 repeater stations is a constituent of excellent maintenance work and has the divergence of operating the petroleum products filled prime mover transmission lines and the pumps in its Pump Stations for more than 200,000 hours as appeared in Figure 1.

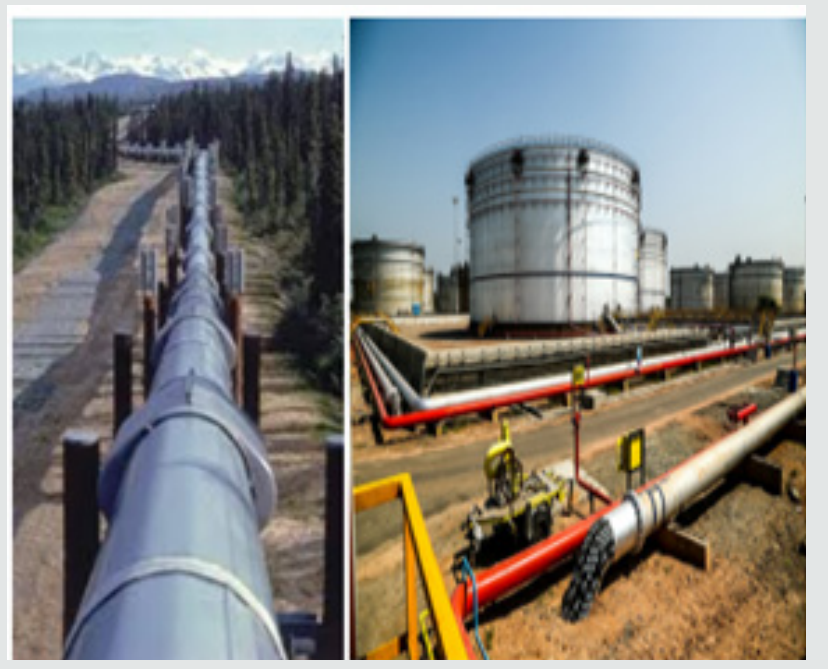

Figure 1: Transmission lines and storage tankers incorporated with SCADA.

\section{Environmental concern and associated risks in oil pipelines}

Environmental trepidations are the major concerns for the exploitation of transmission oil pipelines rather than gathering lines for transporting crude oil for the long run passages [12]. Pipeline protection plays a challenging complex task in the strategy of securing assets. Conversely, examining system dependability and launching optimum maintenance techniques also plays a crucial tedious procedure [13]. The failure rate, which is considered to express consistency of a system, is affected by numerous factors such as the environmental conditions (soil type, onshore/ offshore conditions etc.), internal pipeline influencing variables (the rate of viscosity, speed, chemical composition of oil, etc.), pipe structural characteristics (the material, diameter, length, wall thickness etc.), and maintenance variables (pressure, flow rate, temperature, etc.).

\section{Specific protection techniques for pipelines}

In present trend, oil pipelines are manufactured using steel or plastic tubes with inner diameter range of about 4 to 48 inches (100 to $1,220 \mathrm{~mm})$. In order to safeguard pipes from worst impact influences from abrasion, and corrosion, a various techniques have been handled. Those methodology comes under wood lagging/imported sand padding or by concrete coating/rock shield or covering by high-density polyethylene $[14,15]$.

Crude oil comprehends erratic amounts of paraffin wax and in colder weather situations wax accumulation may transpire within a pipeline. Quite often these pipelines are examined and cleaned by carrying out of pigging by using "pigs" devices also called as "Go-devils"/"scrapers" on a pipeline. "Smart pigs" are known as "intelligence" pigs are used to identify abnormalities in the pipe such as dents, cracking or concerned mechanical damage, or metal loss caused by corrosion. These devices are propelled from pig-launcher stations and pass inside the pipeline which to be received at other down-stream station, which performs operations like removing deposition accrued inside the pipe and records the mechanical condition status of the desired pipes along the transmission [16].

\section{Conclusion}

The diverse category of crude oil that can be pumped through a corresponding pipeline is reliant on the physical characteristics of a pipeline mainly relies on length and diameter. In broad-spectrum, batch process or sequencing is activated to carry one of the refined product or crude oil grade category after one another on the pipeline transfer. Hence, pump stations requisite to be more closely positioned because crude oil inhibits higher viscous than petrol or diesel which could obliges an maximized pressure to maintain the same speed from the inlet station or the pressure at the outlet terminal of a pump station wants to be maximized. But enhancing the pressure at the pump station outlet entails stronger pumps and pipe to endure the operating pressure. It proceeds about 9 to 15 days to transport oil products over 1550 miles, by representing speed approximately at the rate of 2.5 to 5.8 miles per hour.

\section{Conflict of Interest}

All the contributors to this research work have no clashes of attention to announce and broadcasting this article.

\section{Acknowledgment}

This research work is carried out under the Senior Research fellowship received from CSIR (Council for Scientific and Industrial Research) with grant no.678/08(0001)2k18 EMR-I. 


\section{References}

1. Mohammed N, Jawhar N (2011) A fault tolerant wired/wireless sensor network architecture for monitoring pipeline infrastructures. In: 2 nd International Conference on Sensor Technologies and Applications 13: 178-184.

2. McConnell RA, Haswell JV (2011) Pipeline Product Loss Incidents (1962-2010). Report 11/076. The United Kingdom Onshore Pipeline Operators' Association -UKOPA.

3. Priyanka EB, Maheswari C (2016) Parameter monitoring and control during petrol transportation using PLC based PID controller. Journal of Applied Research and Technology 14(2): 125-131.

4. Priyanka EB, Maheswari C, Thangavel S (2018) Remote monitoring and control of an oil pipeline transportation system using a Fuzzy-PID controller. Flow Measurement and Instrumentation 62(3): 144-151.

5. Priyanka EB, Maheswari C, Thangavel S (2018) IoT based field parameters monitoring and control in press shop assembly. Internet of Things 3-4: 1-11.

6. Priyanka EB, Maheswari C, Thangavel S (2019) Remote monitoring and control of LQR-PI controller parameters for an oil pipeline transport system. Proceedings of the Institution of Mechanical Engineers, Part I: Journal of Systems and Control Engineering 233(6): p.0959651818803183.

7. Priyanka EB, Maheswari C, Thangavel S (2018) Proactive Decision Making Based IoT Framework for an Oil Pipeline Transportation System. In: International conference on Computer Networks, Big data and IoT Springer, Cham, pp. 108-119.

8. Subramaniam T, Bhaskaran P (2019) Local intelligence for remote surveillance and control of flow in fluid transportation system. Advances in Modelling and Analysis C 74(1): 15-21.
9. Priyanka EB, Krishnamurthy K, Maheswari C (2016) Remote monitoring and control of pressure and flow in oil pipelines transport system using PLC based controller. In 2016 Online International Conference on Green Engineering and Technologies (IC-GET), IEEE, pp. 1-6.

10. Priyanka EB, Maheswari C, Thangavel S (2017) HMI-PLC Automation for Pressure and Flow Control in Oil Pipelines, ISBN:978-3-659-97459-5, Lap Lambert Academic Publishing, Germany.

11. BSI PD 8010-3:2009, Steel Pipelines on Land Guide to the Application of Pipeline Risk Assessment to Proposed Developments in the Vicinity of Major Accident Hazard Pipelines Containing Flammables. BSI - British Standard Institution.

12. Kiefner JK, Meslob RE, Kiefner BA (2001) Analysis of DOT Reportable Incidents for Gas Transmission and Gathering System Pipelines, 1985 through 1997. Pipeline Research Council International. Report L51830.

13. Kiefner JK, Kiefner BA, Vieth PH (1999) Analysis of DOT Reportable Incidents for Hazardous Liquid Pipelines, 1986 through 1996. American Petroleum Institute Publication, p. 1158.

14.DOT - US Department of Transportation, Pipeline and Hazardous Materials Safety Administration (2015). Pipeline Incident and Mileage Reports.

15. EGIG - European Gas Pipeline Incident Report Group, 2011. $8^{\text {th }}$ Report of the European Gas Pipeline Incident Group 1970-2010. Report 11.R.0402 (version 2).

16. Davis PM, Dubois J, Gambardella F, Sanchez-Garcia E, Uhlig F (2011) Performance of European Cross-country Oil Pipelines - Statistical Summary of Reported Spillages in 2010 and since 1971. CONCAWE. Report no. 8/11.

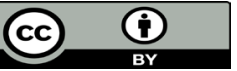

This work is licensed under Creative Commons Attribution 4.0 License

To Submit Your Article Click Here:

Submit Article

DOI: $10.32474 /$ TCEIA.2019.03.000170

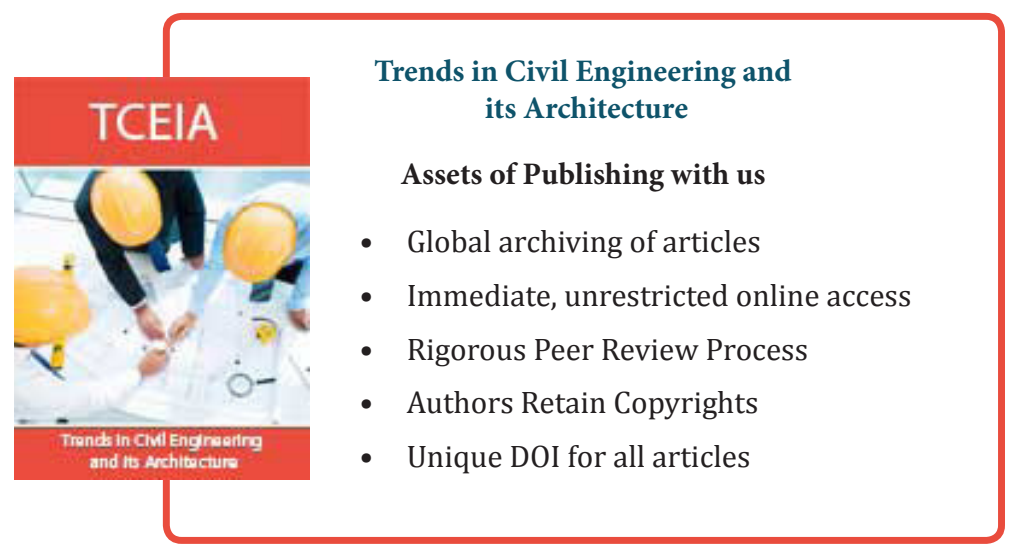

Citation: Citation: Priyanka EB*, Maheswari C, Thangavel S. A Mini Review- Investigation and Study of Risks in Oil Pipeline Construction 